\title{
A Flip Blended Learning Approach for ePUB3 eBook-based Course Design and Implementation
}

\author{
Tina Pingting Tsai ${ }^{1}$, Jyhjong Lin ${ }^{2}$, Lendy Chaoyu Lin ${ }^{2}$ \\ ${ }^{1}$ General Education Center, Hsuan Chuang University, TAIWAN \\ 2 Department of Information Management, Ming Chuan University, TAIWAN \\ Received 10 July 2017 - Revised 2 September 2017 - Accepted 26 September 2017
}

\begin{abstract}
Using digital and internet technologies in recent years has not only provided more education opportunities outside classrooms, but has also gained many attentions as a new theme for prospective learners to acquire knowledge in a more convenient way. In such a new paradigm of the so called e-Learning, many efforts have been made to build web-based learning systems that provide controllable processes of learning activities with desired curricular contents. From the learning perspective, this means that desired contents are delivered with spectacular ways to catch the attention of the learners or to enhance their comprehension on these contents. For this need, we present in this paper a flip blended learning approach for designing, lecturing, and assessing academic courses with ePUB3 eBooks used in learning activities for delivering desired curricular contents. Further, for justifying its validity, the approach employs also an analysis about the effects of using our ePUB3 eBook-based flip blended learning model in academic course learning. For implementation, the approach is applied for the design and instruction of an 'Object-Oriented Concepts' course for freshman students at a Department of Information Management.
\end{abstract}

Keywords: e-learning, flip blended learning, course design, eBook, ePUB3

\section{INTRODUCTION}

For the rapid advances of digital and internet technologies in recent years, providing more education opportunities to learn outside classrooms has gained many attentions as a new theme for prospective learners to acquire knowledge in a more convenient way. In this new paradigm of the so called e-Learning, many efforts have been made to build web-based learning management systems (LMS) (Stone and Zheng, 2014) that provide controllable processes of learning activities with desired curricular contents.

In our best knowledge, e-Learning is managed for concerning what learners really care about that includes the recognition of expected learning objectives and how these objectives are achieved by learning activities under a commitment mechanism (i.e., engaging the achievement of these objectives through a designated process for monitoring and controlling these activities). Many approaches that deal with these needs have been presented; most of which focus mainly on specifying/directing the learning activities, including for instances (1) SCORM (SCORM 2004, 2015; SCORM, 2015) that uses sequencing control modes to represent the learning activities in an activity tree; (2) rule-based systems (Hoyos-Rivera, et al., 2006; Marinković and Tomaš, 2011) that use access rules to specify and direct a specific process of learning activities; (3) relationship-based systems (Romero, et al. 2014) that use logic relationships to define a course structure with the relationships among its containing course components; and (4) workflow-based systems (Cao, et al., 2009) that employ the power of workflows to define a stream of activities that constitute a learning process.

In general, these approaches support well the provision of a controlled process of learning activities. However, they have the following deficiencies: (1) their mechanisms do not address the delivery ways of desired contents in the controlled process (i.e., how these contents are delivered with spectacular ways for achieving expected objectives); and (2) there are no discussions about the implementation of such delivery ways by using selected 


\section{Contribution of this paper to the literature}

- A flip blended learning approach is proposed for designing, instructing, and assessing academic courses with the newly introduced ePUB3 eBooks used in learning activities and delivering curricular contents.

- As a pilot discussion about using ePUB3 eBooks, the approach addresses the learning activities under the flip blended learning model, the curricular contents in respective eBooks to be delivered under these activities; and the suitable ePUB3 functions embedded in such eBooks for supporting the actions of these activities and the deliveries of desired curricular contents.

- As blended learning is widely accepted, our approach with ePUB3 eBooks can enhance the flip execution model of blended learning with a more flexible and attractive environment.

publication formats. In our view, delivering desired contents with spectacular ways is beneficial for its being able to motivate the learners to pay more attentions on the reading of these contents. For instances, keeping contents vivid by employing such internals as contrast colors and bright pictures can strengthen the richness of these contents for stimulating the learners' different senses (Ortony, et al., 1990); further, keeping contents interactive by imposing interactive media such as browsing links and reminding notes can help the learners to initiate or react for a communication for motivating their mindfulness on these contents.

For this need, we have presented in our previous work (Lin, et al., 2017) some discussions about the delivery ways of desired contents, the implementation of these ways by the standardized ePUB3 format for eBook publications (ePUB3 Overview, 2011), and finally the presentation of these constructed ePUB3 eBooks by the referenced Readium reader (Readium reader for ePUB3, 2017). Continuing our work for using these functions as a blended learning (Bonk and Graham, 2005) in academic courses, we present in this paper a flip blended learning approach for designing, lecturing, and assessing academic courses with ePUB3 eBooks used in learning activities for delivering desired curricular contents.

In general, as a pilot discussion about using ePUB3 eBooks in learning activities, the approach is based on the blended course design issues in (McGee and Reis, 2012) as well as on the well-known ASSURE approach in (Smaldino, et al., 2012) with the following extensive considerations: (1) identifying the learning units of the course and the learning activities under the flip blended learning model for each lesson of a unit (i.e., how the lesson proceeds in the context of the flip blended learning); (2) designing the curricular contents in respective eBooks to be delivered under these learning activities; (3) specifying the suitable ePUB3 functions embedded in such eBooks for supporting the actions of these learning activities (e.g., initiating/reacting their actions) and the deliveries of desired curricular contents; and (4) employing an analysis about the effects of using the extensive ePUB3 eBookbased flip blended learning model for justifying its validity.

For implementation, the approach is applied for the design and instruction of an 'Object-Oriented Concepts' course for freshman students at a Department of Information Management. Note that there are already many discussions about the course design in blended learning (Banditvilai, 2016; Eke and Bell, 2010; Hoic-Bozic, 2009; Hybrid Course Development, 2017; Li and Liu, 2010; Online and Hybrid Course Development Guidelines, 2011; Poirier, 2010; Rossett, et al., 2003; Ward and Draude, 2009). However, due to the differences among their supportive environments and applicable domains, adequate statements on their dis/advantages are quite difficult. Therefore, we do not address herein the comparisons between these existing approaches and ours.

This paper is organized as follows. The background and motivation of our approach is firstly overviewed. Our approach is then presented where its application on the 'Object-Oriented Concepts' course is also implemented. Afterwards, the validity analysis about the effects of using our ePUB3 eBook-based flip blended learning model is discussed. Finally, the conclusions and future work are presented.

\section{BACKGROUND AND MOTIVATION}

\section{Blended Learning}

In general, blended learning (Bonk and Graham, 2006) supports a learning process with a mixture of various learning activities such as face-to-face, media-guided, and internet-based lectures. It provides the learners with an efficient learning environment that encompasses such spectacular learning aspects as online and traditional learning platforms, media deliveries of learning contents, flexible learning models, and self-conducted learning activities. Its main focus is to provide an attractive learning circumstance for motivating the learners and enhancing their learning effectiveness (Alonso, et al., 2005; Bersin, 2004; Thorne, 2003). From this mixture of various learning activities and encompassed learning aspects, blended learning can have many execution models (@DreamBox_Learn, 2013; Kharbach, 2014) such as Face-to-Face Driver, Flip, Rotation, Online Lab, Flex, and Online Driver: 
1. Face-to-Face Driver model - the introduction of online instruction is decided on a case-by-case basis, meaning only certain students can participate in any form of blended learning. This model allows students to progress at their own pace in using technology in the classroom.

2. Flip model - technology is employed to reverse the traditional role of classroom time for encouraging students to proceed with an individualized learning and help; student-teacher interaction can also be improved. Although learning contents are available in class, they are mainly designed in such a way to be accessed outside class which is a great way for students to learn at their own pace.

3. Rotation model - students rotate at fixed points in time between different learning stations, at least one of which is an online learning station; other stations might include activities such as small-group or full-class instruction, group projects, individual tutoring, and pencil-and-paper assignments. Some implementations involve the entire class alternating among activities together; whereas others divide the class into smallgroup rotations.

4. Online Lab model - students learn entirely online but travel to a dedicated computer lab to complete their course works under the supervision of lab assistants. This not only allows schools to offer courses for which they have no or not enough teachers, but also allows students to learn at their own pace and in a subject area that suits them.

5. Flex model - online learning forms the backbone of the model, even if it directs students to act on learning activities at times, students are able to move in a flexible way through different learning modalities with the goal of optimizing their learning experience based on their specific needs. Each student in essence has a customized and fluid schedule among learning modalities. The teacher provides necessary face-to-face supports on a flexible and adaptive as-needed basis through activities such as small-group instruction, group projects, and individual tutoring.

6. Online Driver model - at the opposite end of the spectrum from face-to-face driver, students learn remotely and learning contents are primarily delivered via an online platform. Although face-to-face helps are optional, students can usually consult with teachers online if they have questions. This model is ideal for students who need more flexibilities and independence in their learning schedules.

\section{Theories of Learning}

In the context of learning, there are many theories or approaches that not only stand with their own viewpoints, but also complement each other and may even overlap. In general, any learning systems seem to be composed of the elements from the three theories: behaviourism, cognitivism, and constructivism (Ally, et al., 2004). The behaviourism observes how learning is affected by the behaviour of the teacher or other external factors. Students require suitable approvals and supports for their learning in an incremental or even repeated process. The cognitivism perceives learning as a mental process. Here, learning is an active process of transforming experiences into organized concepts with an emphasis on the differences in abilities and motivations between students. The stress is on how students perceive, interpret, store, and memorize information from learning contents. The constructivism recognizes learning as an active process of constructing meaning. Students do not memorize what was said by the teacher. Instead, they construct they own words of the learning contents. Students may get helps to construct their own knowledge via a mixture of reflection, discussion, and exchange with teachers and other students. High-quality learning environments in general should be based on the mixture of these three theories of learning (Mishra, 2002; Johnson, et al., 2002). Nevertheless, it should be noted that constructivism is the most widely accepted model of learning in education today (Morphew, 2000) since it emphasizes on an active student-centric model with students actively involved in the learning process.

\section{ePUB3 eBook}

In learning systems, delivering learning contents with spectacular ways is beneficial for its being able to motivate the learners to pay more attentions on the reading of these contents. In addition to the many existing contents delivery ways such as internet-based, multimedia, social media, and virtual/augmented reality (Bermejo, 2005; Blank, et al., 2003; Bressler and Bodzin, 2013; Caeiro-Rodríguez, et al., 2013; Chen, et al., 2017; Chen, et al., 2015; Clark and Mayer, 2011; Denner, et al., 2012; Gao and Liu, 2010; Lee, et al., 2016; Mao, et al., 2017; Martens, et al., 2004; Romero-Hall, et al., 2016; Stash, et al., 2004), the standardized ePUB3 format (ePUB3 Overview, 2011) is a newly introduced specification as a distribution and interchange format standard for digital publications and documents. It defines a means of representing, packaging, and encoding structured and semantically enhanced Web contents - including HTML5, CSS, SVG, images, and other resources - for distributions in a single-file format. As such, ePUB3 has been widely adopted as the format for digital books (or the so called ePUB3 eBooks), and its significant features increase the format capabilities to support a wider range of publication requirements, including complex layouts, rich media, interactivities, and global typographies. The expectation is that ePUB3 eBooks can be 
used in education for supporting the actions of learning activities (e.g., initiating/reacting these actions) as well as the deliveries of learning contents.

It should be noted that in the context of eBook publications, there are already many publication formats in the literature, including for instances (Wikipedia, 2017) DAISY (Digital Accessible Information System) proposed by DAISY Consortium, ePUB by IDPF (International Digital Publishing Form), iBook by Apple, AZW and KF8 (Kindle Format 8) by Amazon.com, XMDF by Sharp, CEBX by Baidu, PDF by Adobe, etc. Among them, in our best knowledge, PDF is currently the most spread format due to its allowing easy reading and sharing of documents within a fixed layout. However, it has also some drawbacks (Binas, et al., 2012) as follows.

1. It is print oriented and hence not easy for rendering rich media and interactivities.

2. Its layout is fixed and hence not suitable for presenting reflowable and resizable contents.

3. It is used for static printed media and hence not feasible for supporting functional requirements such as communicative media and access tracking.

Therefore, considering these drawbacks and the similar restrictions in other formats, we focus herein on the ePUB3 format due to its most attractive specification (note that its specification 1.0 was earliest released in 1999, then revised as version 2.0 in 2007, and finally upgraded as version 3.0/3.1 in 2011/2015). For examples, it is based on Web 2.0 techniques (Vossen and Hagemann, 2010) and hence employs static HTML5/CSS3 features for providing rich content presentations and also dynamic JavaScript mechanisms for rendering interactive contents, communicative media, and action/access tracking. In addition, it is an open format and supports well multiple language representations (e.g., Japanese, Korean, and Chinese). Finally, it has been approved as an international standard in ISO/IEC TS 30135 (ISO/IEC TS 30135, 2014) by ISO/IEC JTC1 SC34 (International Standardization Subcommittee for Document Description and Processing Languages) (ISO/IEC JTC1 SC34, 2014). As such, the possible compatibility issues about its significant features can be solved by deploying standard-compatible readers such as the referenced Readium reader (Readium reader for ePUB3, 2017).

\section{Motivation of Our Approach}

The goal of our flip blended learning approach is to take advantage of the above three paradigms for providing students with better learning environments where ePUB3 eBooks are used in the learning activities for delivering curricular contents. For this need, the following four perspectives are extensively considered:

1. In order to promote the student-centric learning and also enhance the independent learning abilities of students, the flip blended learning model will be adopted for designing the learning activities in each lesson unit of the course (i.e., how such a lesson proceeds in the context of the flip blended learning). As in the wellrecognized flip model, learning contents are available not only in the lecture at the classroom, they are also available online before the lecture for students to preview at their own pace outside the classroom to enhance their independent learning abilities.

2. When designing the learning activities and desired curricular contents, the three theories of learning will be carefully imposed for achieving the objectives of the course under the flip blended learning model. As stated above, high-quality learning designs are in general based on the mixture of these three theories of learning; their adequate use in each lesson unit of the course (i.e., how such a lesson proceeds with desired contents delivered before, within, and after its lecture) will be specifically addressed.

3. With the designed learning activities and curricular contents, eBooks will be created with suitable ePUB3 functions embedded for supporting the actions of these learning activities (e.g., initiating/reacting their actions) and the deliveries of these curricular contents. In general, many ePUB3 functions can be considerably embedded in the eBooks: (1) as presented in our previous work (Lin, et al., 2017), supportive functions can be embedded in the textual contents such as pictures, videos, referential links, guided readings, automatic repetitions, exercises, assignments, tests, and questionnaires; and (2) for supporting dynamic behaviours, more enhanced functions can also be embedded such as communications among individuals (e.g., group-based discussions or information sharing among the teacher and students) and action/access tracking of pages/embedded functions (e.g., tracking of actions/accesses on textual pages or functions embedded in these pages).

4. With the ePUB3 eBooks used in the actions of learning activities and the deliveries of curricular contents, the effects of using the extensive ePUB3 eBook-based flip blended learning model will be analysed for justifying its validity. In general, as a usual way in other approaches (Chen and Chen, 2014; Ram and Sinha, 2017; Wen, et al., 2016; Zhang, et al., 2016), such an analysis can first be based on the online questionnaires and in-person interviews with students for validating how these students think about this model. After then, however, it can also be enhanced by extending the concept of evaluating students' class participation (Chen and Chen, 2014) with both of the action tracking of learning activities and the access tracking of learning contents. As one may 
conceive, such an enhanced tracking can reveal more details about how these students participate in the actual instruction for validating the effects of their joining the ePUB3 eBook-based flip blended learning model.

\section{Characteristics of Our Approach}

With the above considerations, our ePUB3 eBook-based flip blended learning approach can provide students with an eBook-centric learning environment where the actions of flipped learning activities and the deliveries of learning contents are supported by those ePUB3 functions embedded in the imposed eBooks. It is noticed that although there are already many flipped models for the computing courses in higher education (Chen and Chen, 2014; Ram and Sinha, 2017; Wen, et al., 2016), more spectacular characteristics can be found in our approach for making it support better the flip blended learning:

1. These existing models address mainly learning activities where learning contents are delivered by traditional media such as videos and video clips. For examples, Chen et al. (Chen and Chen, 2014) propose an activity matrix to help teachers determine which learning activities can be considerably taken in a course such as (1) previews/reviews before/after the class; and (2) lectures, group discussions/sharing/reflections, quizzes, tests, exercises, reports, and presentations in the class. Further, Zhang, et al. (Zhang, et al., 2016) present also similar learning activities in a course such as (1) previews, assignments, and exercises before the class; and (2) lectures, group discussions/ questions/presentations/debates, tests, and case studies in the class. However, compared to these models, our approach employs more powerful ePUB3 features that support not only the online actions of these commonly adopted flipped learning activities by various actionrelevant ePUB3 functions such as assignments, exercises, tests, and communications, but also the spectacular online deliveries of learning contents by such access-relevant ePUB3 functions embedded in the textual contents as pictures, videos, referential links, guided readings, and automatic repetitions.

2. These models recognize the importance of the class participation and hence record the actions taken in learning activities to analyse the engagement and performance of students. Compared to these models, nonetheless, our approach has more powerful ePUB3 features that support not only the action tracking of learning activities by respective action-tracking ePUB3 functions for tracking the students' actions on assignments, exercises, tests, and communications, but also the access tracking of learning contents by respective access-tracking ePUB3 functions for tracking the students' accesses on textual pages or embedded pictures, videos, referential links, guided readings, and automatic repetitions.

3. For validating the effectiveness of their flipped activities, these models employ various validity analysis ways such as online questionnaires, in-person interviews, and class participation tracking. Compared to these models, as in the above, our approach employs more powerful ePUB3 features that support not only the online actions of these analysis ways by both of the validity-relevant ePUB3 function questionnaires and the respective action-tracking ePUB3 functions for tracking the students' actions on assignments, exercises, tests, and communications, but also an enhanced access analysis by those aforementioned access-tracking ePUB3 functions for tracking the students' accesses on textual pages or embedded pictures, videos, referential links, guided readings, and automatic repetitions.

In summary, with the above spectacular characteristics, our approach can enhance the flip blended learning process for the computing courses in higher education by providing more powerful action-/access-/validityrelevant and action-/access-tracking ePUB3 functions for supporting, controlling, and validating the actions of flipped learning activities and the deliveries of learning contents.

\section{THE FLIP BLENDED LEARNING APPROACH}

In general, as shown in Figure 1, our approach is based on the design issues in (McGee and Reis, 2012) as well as on the well-known ASSURE approach in (Smaldino, et al., 2012) with the following six steps: 


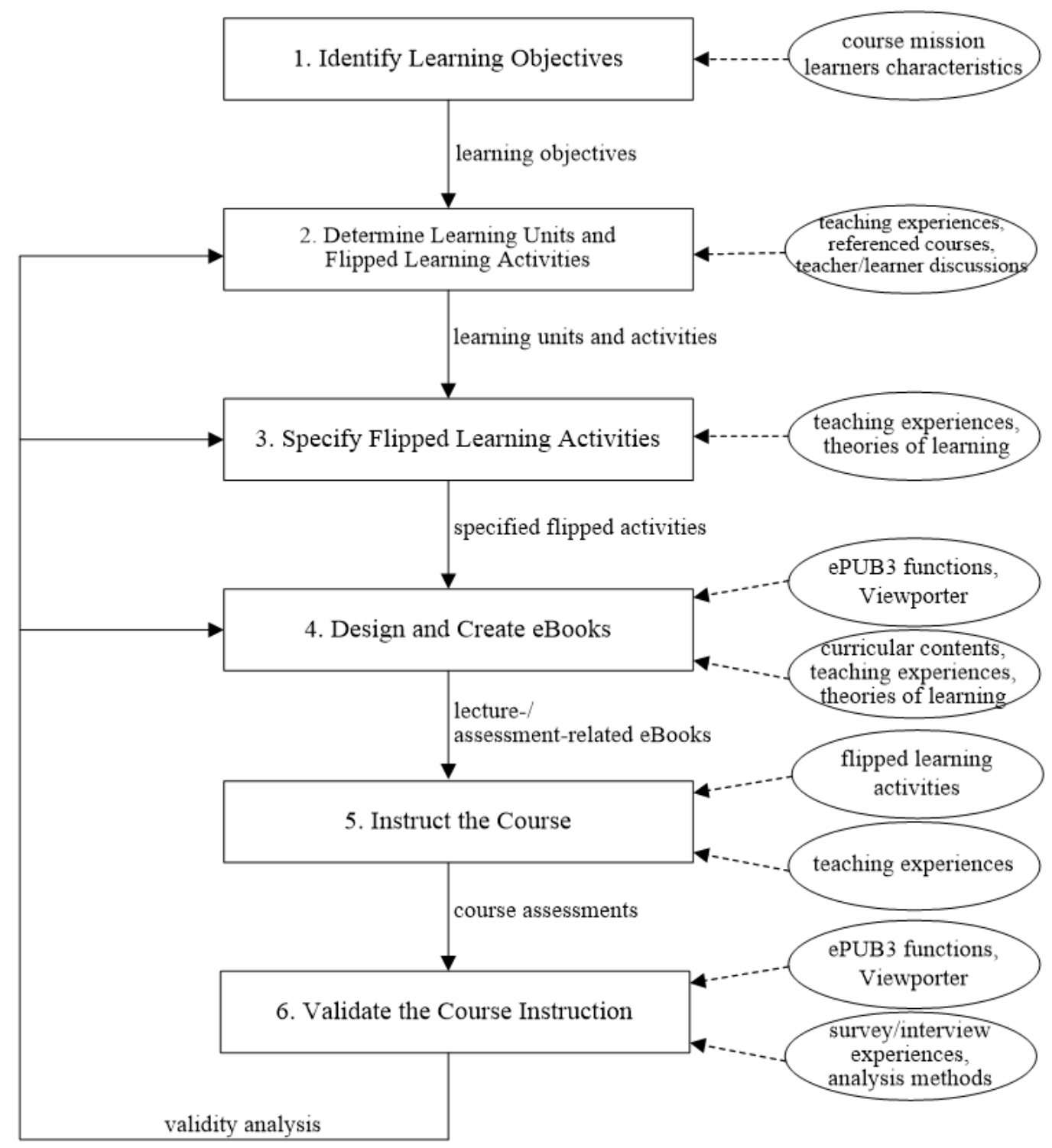

Figure 1. The ePUB3 eBook-based Flip Blended Learning Approach

1. Identify Learning Objectives - This step addresses the pedagogical purposes of the course for the learners to get such as what knowledge they acquire, what practices they experience, and what capabilities they possess. In order to identify these objectives, two perspectives may be considered as follows.

(1) The mission of the course is referenced for addressing the expected achievement which is usually approved by the institute via formal procedures. For instance, an 'Object-Oriented Concepts' course is commonly designed in a computer science department for providing freshman students with the basic capabilities of designing object-oriented programs. This course is thus approved with the mission making students possess the capabilities of designing object-oriented programs.

(2) The characteristics of students can be considered for clarifying the feasibility of any specific objectives identified for achieving the above approved mission. These characteristics may in general include (1) the attributes of students such as academic abilities and interests; (2) their prior competencies such as experiences of designing programs; and (3) their suitable learning styles such as direct instruction, cooperative learning, inquiry-/project-based learning, and seminar.

Afterwards, the feasible objectives for accomplishing the course mission may be identified as below.

(1) Students understand the syntax and semantics of the basic concepts in object-oriented programming languages.

(2) Students comprehend the design of object-oriented programs by using these basic concepts. 
2. Determine Learning Units and Flipped Learning Activities - This step focuses on three perspectives:

(1) The learning units of the course that address the units to be necessarily lectured in the course. For instances, for an 'Object-Oriented Concepts' course, there may have such learning units as 'Class \& Object', 'Inheritance \& Polymorphism', 'Method \& Overloading', and 'Abstraction \& Encapsulation'. In general, this can be determined by many ways such as the teaching experiences of the teacher, the references from other relevant courses, and the possible discussions between the teacher and those students who have ever taken this course.

(2) The flip learning model of the course that specifies how the course proceeds before, within, and after each lesson of a unit (i.e., a lesson). In general, in the context of the flip blended learning, this may include (a) the learning phases of each lesson such as before, within, and after the lesson; (b) the learning ways used in each lesson such as individual, group, and seminar ways; (c) the learning types in each lesson like instructive, and inquiry-/project-/problem-based types; (d) the learning modes used in each lesson such as face-to-face, online, and mixed (i.e., both of face-to-face and online) modes; and (e) the learning locations of each lesson such as inside- and outside-classroom.

(3) The flipped learning activities of the course that focus on the necessary activities for completing and assessing each lesson under the flip learning model. In general, in the context of the flip blended learning, these activities can be divided into three phases: before, within, and after a lesson. For instances, considering the possible activity flow of a flip learning lesson, the following flipped learning activities may be identified:

Before the lesson

(B.1) An individual, instructive, online, and outside-classroom preview of curricular contents (e.g., start from 3 days before the lesson).

(B.2) An individual, instructive, online, and outside-classroom assignment about the previewed contents (e.g., completed within 3 days before the lesson).

Within the lesson

(W.1) An individual, instructive, online, and inside-classroom pre-lecture test at the beginning of the lesson (for verifying the effectiveness of the above preview).

(W.2) An individual, instructive, mixed, and inside-classroom supplemental lecture from the teacher (e.g., addressing the problems or mistakes exposed from the above assignment or test) within the lesson.

(W.3) Various individual/group, problem-based, mixed, and inside-classroom exercises (e.g., constructing internalized knowledge through the individual-/group-based process of thinking-discussionreflection-consolidation) within the lesson.

(W.4) An individual, project-based, online, and inside-classroom post-lecture test at the end of the lesson (for verifying the learning effectiveness of the lesson).

After the lesson

(A.1) An individual, instructive, online, and outside-classroom review of curricular contents (e.g., within 3 days after the lesson).

3. Specify Flipped Learning Activities - This step focuses on the detailed specification of those flipped learning activities identified above. Since eBooks are used in these activities for supporting their actions, suitable ePUB3 functions are specifically embedded in these activity-accessed eBooks. For this need, the following perspectives are considered:

(1) In addition to the aforementioned features of these learning activities such as their ways, types, modes, and locations, their other attributes may also need to be identified, including for examples their duration times, sequencing relationships, and possible resources (e.g., supportive teaching assistants).

(2) For achieving the course objectives, the three theories of learning need to be employed in the lecturerelated activities. For instances, the above B.1 W.2, and A.1 activities for the preview, supplemental lecture, and review of curricular contents may employ the 'behaviourism' for making it in an incremental manner for previewing, lecturing, and reviewing, and also the 'cognitivism' for making students be able to perceive, interpret, and consolidate these curricular contents. Further, the above W.3 activity for giving individual/group and problem-based exercises may employ both of the 'cognitivism' and 'constructivism' for making students be able to construct their internalized knowledge from these curricular contents.

4. Design and Create eBooks - This step focuses on the design and creation of eBooks for supporting the actions of those learning activities specified above. In particular, desired curricular contents and ePUB3 functions 
need to be embedded in these eBooks for realizing the theories of learning employed in their hosting activities. In general, in the context of the flip blended learning, these eBooks can be divided into two categories: lecture- and assessment-related. In our examples:

(1) For the above B.1, W.2, W.3, and A.1 activities about the preview, supplemental lecture, exercises, and review of curricular contents, a lecture-related eBook may be designed for supporting the actions of these activities. In particular, curricular contents are first specified in the eBook for delivering the necessary knowledge about the learning objectives, and supportive functions such as pictures, videos, automatic repetitions, exercises, and communications are then embedded in these contents to enhance their capabilities on the desired theories of learning for taking these activities (as stated above, students may first perceive and interpret these curricular contents, and then construct their internalized knowledge from these contents via the mixed use of the three theories of learning: 'behaviourism', 'cognitivism', and 'constructivism').

(2) For the above B.2, W.1, and W.4 activities about the assessments of the lesson, three assessment-related eBooks may be designed for respectively taking these assessments. More specifically, assessment contents are first specified in these eBooks for achieving the desired assessment purposes, and supportive functions such as assignments and tests are then embedded in these contents to deliver the desired assessments.

Finally, with the detailed design of curricular/assessment contents and ePUB3 functions in these eBooks, their creation can then be completed by some well-known development tools such as ViewPorter (ViewPorter, 2017), InDesign (Adobe InDesign, 2017), Sigil (Sigil, 2017), and Calibre (Calibre, 2017). Among them, in our best knowledge, ViewPorter is the most popular one for its powerful and convenient features to support the creation of high quality textual contents and embedded ePUB3 functions.

5. Instruct the Course - This step addresses the actual instruction of the course. In general, the instruction is taken in accordance with the specified (times and sequences of) learning activities in each lesson of the course where desired curricular/assessment contents in eBooks are delivered for completing the lesson. As specified above, the learning activities in each lesson can be taken under the three sequential phases: before, within, and after the lesson where:

(1) The lecture-related eBook is used for students to get the preview (activity B.1), lecture (activity W.2), exercises (activity W.3), and review (activity A.1) of curricular contents.

(2) Assessment-related eBooks are employed for the teacher to assess the effectiveness (activities B.2, W.1, and W.4) of the lesson.

In particular, it should be noticed that exercises (activity W.3) within a lesson are usually taken repeatedly in an individual/group and problem-based manner for students to construct their internalized knowledge about the curricular contents through the repeated thinking-discussion-reflection-consolidation processes.

6. Validate the Course Instruction - This step focuses on the validity analysis about the effects of using the ePUB3 eBook-based flip blended learning model in the actual course instruction. In general, the analysis can include the following two ways:

(1) As a usual way in other approaches (Chen and Chen, 2014; Ram and Sinha, 2017; Wen, et al., 2016; Zhang, et al., 2016), the analysis can first be based on the online questionnaires and in-person interviews with students for making the teacher be able to validate how these students think about the instruction (e.g., dis/advantages). In our examples, this way may be imposed (note that a questionnaire eBook is designed and created for delivering the desired questionnaires) for validating how students think about using our ePUB3 eBook-based flip blended learning model in their learning.

(2) In addition to questionnaires and interviews, the analysis can also be enhanced by extending the concept of evaluating students' class participation (Chen and Chen, 2014) with both of the action tracking of learning activities and the access tracking of learning contents. As one may conceive, such an enhanced tracking can validate the effects of the instruction by revealing how students participate in the instruction (e.g., actively/inactively take the actions of learning activities or access the deliveries of curricular contents). For instances, if students have shown their 'active' accesses on the deliveries of a specific part of curricular contents (e.g., reading textual pages, watching embedded videos, or accessing referential links), this means that the actual instruction is valid for students to learn by accessing this desired part of curricular contents under the ePUB3 eBook-based flip blended learning model. In contrast, however, if students have shown their 'inactive' accesses on the deliveries of a specific part of curricular contents, this means that the actual instruction is not valid for students to learn by accessing this desired part of curricular contents. This also implies that some possible ways for encouraging or forcing students to access these desired contents may need to be imposed for improving the accesses in later actual instructions. 


\section{THE IMPLEMENTATION OF THE APPROACH}

In this section, we implement our approach by applying it on the design and instruction of an 'Object-Oriented Concepts' course for freshman students at a Department of Information Management.

\section{The Course Design}

As shown in Tables 1 and 2, the course is designed with the following sections based on the first four steps of our approach (note that for illustration, two's out of the four units learning activities are specified with their identified features):

1. Course Name - Object-Oriented Concepts.

2. Objectives - (1) Students understand the syntax and semantics of the basic concepts in object-oriented programming languages; and (2) Students comprehend the design of object-oriented programs by using these basic concepts.

3. Learning Units - four learning units about object-oriented concepts, i.e., Class \& Object, Inheritance \& Polymorphism, Method \& Overloading, and Abstraction \& Encapsulation.

4. Flip Learning Model - 5 learning activities for each lesson of a unit under the flip learning model, i.e., (1) an outside-classroom online preview before the lesson, (2) an inside-classroom online pre-lecture test at the begin of the lesson, (3) the inside-classroom lesson lecture with a mixed mode of students' online learning at their own pace and supplemental lecturing from the teacher, (4) inside-classroom exercises during the lesson with the same mixed mode as above, and (5) an inside-classroom online post-lecture test at the end of the lesson.

5. Activities of Units - learning activities of each lesson of a unit with their features specified such as their ways, types, modes, locations, times, sequences, resources, and imposed theories of learning (Table 1), and ePUB3 functions used for supporting their actions (Table 2). 
Table 1. The design of an 'Object-Oriented Concepts' course (features of learning activities)

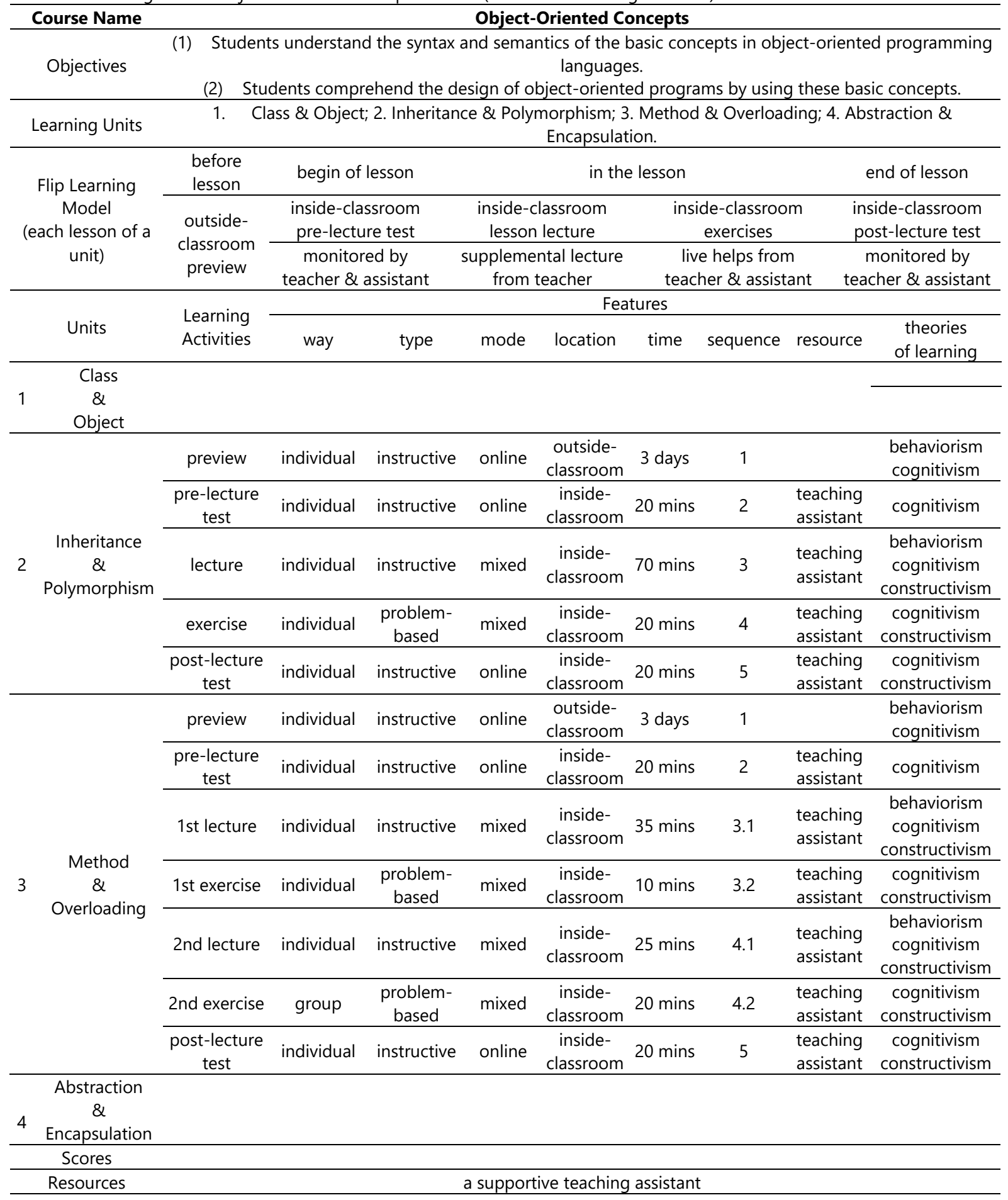


Table 2. The design of an 'Object-Oriented Concepts' course (supportive ePUB3 functions)

\begin{tabular}{|c|c|c|c|c|c|c|c|c|c|c|}
\hline \multirow{3}{*}{\multicolumn{2}{|c|}{$\begin{array}{c}\text { Course Name } \\
\text { Units }\end{array}$}} & \multicolumn{9}{|c|}{ Object-Oriented Concepts } \\
\hline & & \multirow{2}{*}{ Activities } & \multicolumn{8}{|c|}{ ePUB3 functions } \\
\hline & & & picture & video & link & reading & repetition & exercise & communication & test \\
\hline 1 & Class \& Object & & & & & & & & & \\
\hline \multirow{5}{*}{2} & \multirow{5}{*}{$\begin{array}{c}\text { Inheritance } \\
\& \\
\text { Polymorphism }\end{array}$} & preview & $v$ & $V$ & & & $V$ & & & \\
\hline & & pre-lecture test & & & & & & & & $V$ \\
\hline & & lecture & $v$ & $v$ & & & $v$ & & & \\
\hline & & exercise & & & & & & $v$ & & \\
\hline & & $\begin{array}{c}\text { post-lecture } \\
\text { test }\end{array}$ & & & & & & & & $v$ \\
\hline \multirow{7}{*}{3} & \multirow{7}{*}{$\begin{array}{l}\text { Method } \\
\& \\
\text { Overloading }\end{array}$} & preview & $v$ & $V$ & & & $v$ & & & \\
\hline & & pre-lecture test & & & & & & & & $V$ \\
\hline & & $1^{\text {st }}$ lecture & $v$ & $v$ & & & $v$ & & & \\
\hline & & $1^{\text {st }}$ exercise & & & & & & $v$ & & \\
\hline & & $2^{\text {nd }}$ lecture & $V$ & $V$ & & & $v$ & & & \\
\hline & & $2^{\text {nd }}$ exercise & & & & & & $V$ & $V$ & \\
\hline & & $\begin{array}{c}\text { post-lecture } \\
\text { test }\end{array}$ & & & & & & & & $v$ \\
\hline 4 & $\begin{array}{c}\text { Abstraction } \\
\& \\
\text { Encapsulation }\end{array}$ & & & & & & & & & \\
\hline
\end{tabular}

6. Curricular Contents - desired curricular contents in lecture-/assessment-related eBooks for instructing a lesson where ePUB3 functions are embedded in the textual contents of these eBooks. For illustration, Figures 2 - 8 present part of the eBooks used for a lesson of the 'Method \& Overloading' unit where

(1) For assisting the preview before and the supplemental lecture within the lesson, pictures, videos, and automatic repetitions are widely embedded in a lecture-related eBook as shown in Figures 2, 3, 5, 6, 7.

(2) For supporting the individual/group exercises within the lesson, exercises and communications are also embedded in the lecture-related eBook as shown in Figure 4 (individual exercise) \& Figure 6 (group exercise).

(3) Figure 8 shows the pre-/post-lecture tests at the begin/end of the lesson via the ePUB3 tests function in two assessment-related eBooks.

7. Scores - the scores of students through tests and exercises.

8. Resources - a supportive teaching assistant. 


\section{學習目標}

1. 宣告Method, 使用參數並回傳結果

2. 宣告 static methods 與 variables

3. 建立 overloaded method

4. 了解Java如何傳派(pass)參数/變数 video

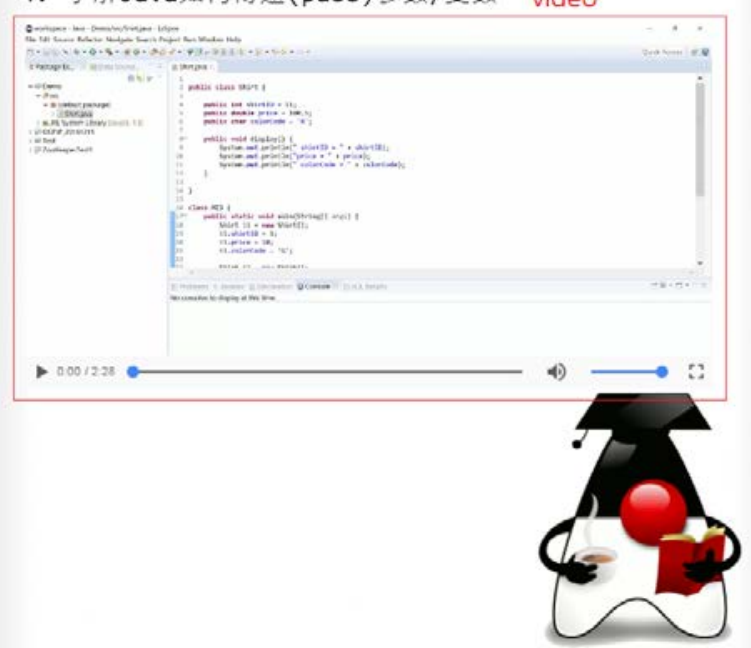

JAYA SE7/8 OCAJP. CH19

\section{宣告 Method·使用炵數並回傳結果}

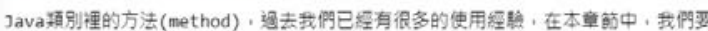
做更进一步的介绍。

1.宣告方法

方法的竡等珸法:

唒法

[modifiers] return_type method_identifier ([arguments] ) \{ method code block

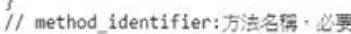

// return type: 回傳型明 - Q 2 要

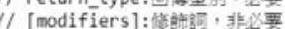

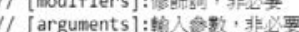

is.

1 class shirt public void display ()(

$4 \quad \vec{j} / /$ end of display method

5 3

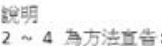

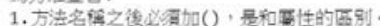

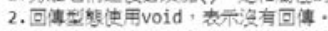

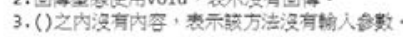

2. 呼叫方法

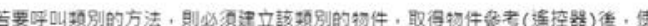
用 $r$. 逜算子, 呼叫剘方法・如下:

Figure 2. The eBook page 1-2 with an embedded video

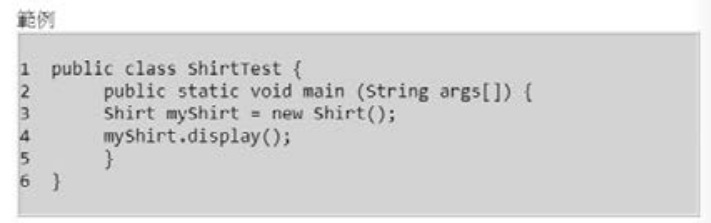

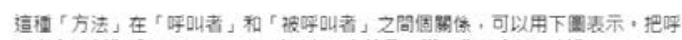

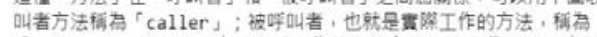

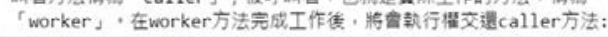

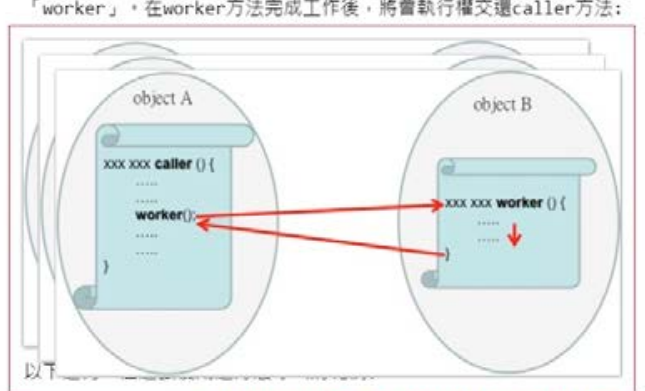

呼叫者(caller): pictures with automatic repetition

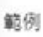

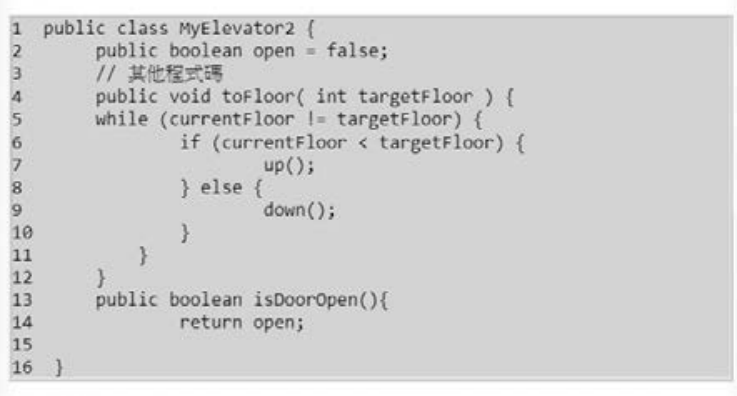

被宇叫热(worker):

17 public class MyElevatorJumpTest public static void main(String[] args) f MyElevator2 test $=$ new MyElevator 2(); test. tofloor(5): \} boolean isopen $=$ test. isDooropen () ; \}

战朋

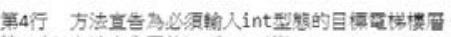

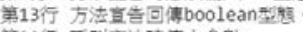

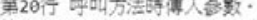

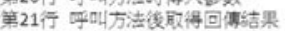

Figure 3. The eBook page 3-4 with an embedded automatic repetition 


\section{IAVA SE $7: 8$ OCAIP $\quad$ CH 10}

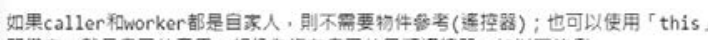

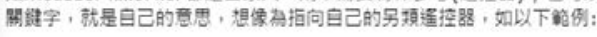

等倒

public class Elevator \{ private boolean dooropen=false; public boolean is booropen() return dooropen

public void opendoor()

I/ check if door already open

if ( 1 this.isDooropen( ) ) (

$10+11-$

\}

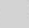

s배요

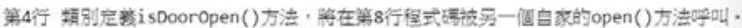
第8 行 使用this

\section{使用method的好處}

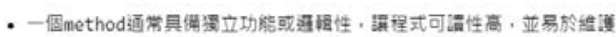

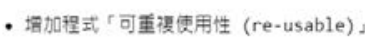

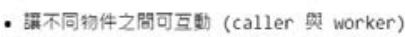

\section{宣告 static methods 與 variables}

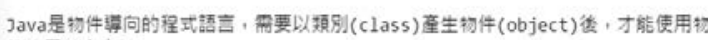
件的電珄和方法。
Jaya赭的static

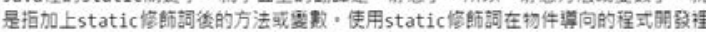

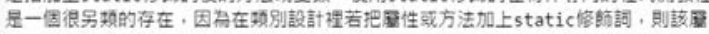

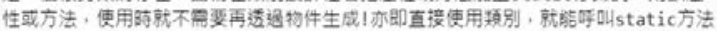
和整数.

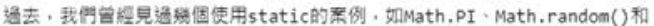

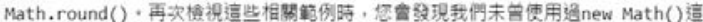

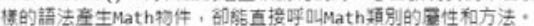

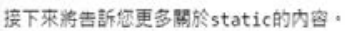
Given: public class rest public static void main(string[] args) (
pass Test m2();
Test.m2();$$
\text { m3(); }
$$

\} public static void $\mathrm{m} 2()(1)$ public void $\mathrm{m} 3()$ (

$$
\text { m1. (); }
$$
Test, m2 () ; m4();

$$
\text { Test.m4(); }
$$

public void $m 4()$ ( )

Which three lines are illegal

$$
\begin{aligned}
& \text { A ine } 5 \\
& \text { (B) ine } 6 \\
& \text { C ine } 10 \\
& \text { (D) ine } 11 \\
& \text { C) ine } 13
\end{aligned}
$$

5

Figure 4. The eBook page 5-6 with an embedded individual exercise

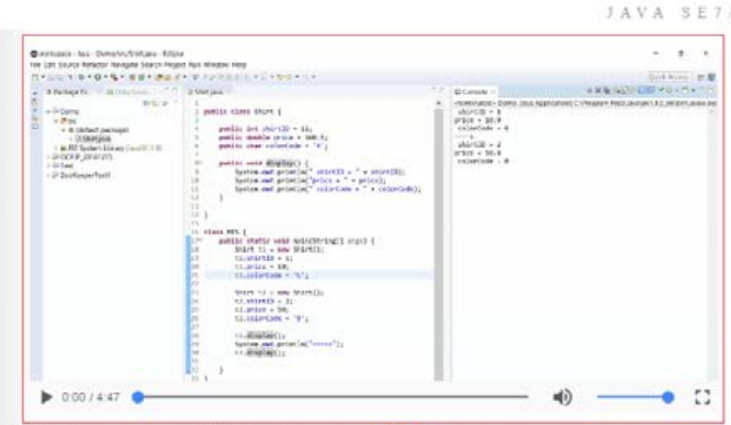

\section{沒有 static 時的情況证等}

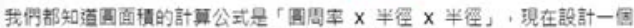

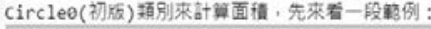

public class circle

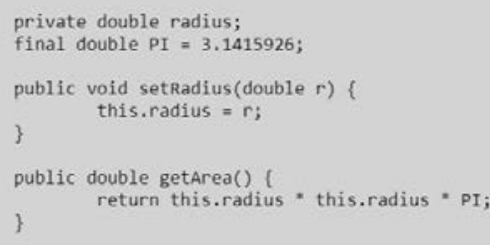

Figure 5. The eBook page 7-8 with an embedded video

\section{使用 static 來解決問题}

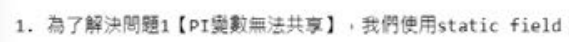

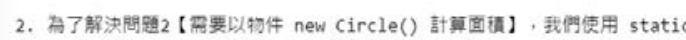
method .

所以class 改版如下:

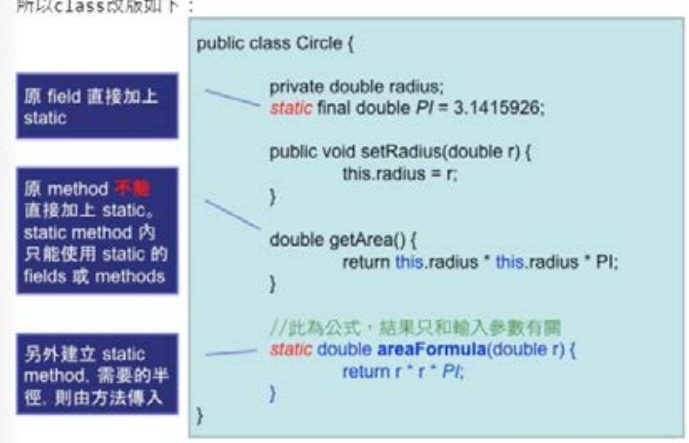

\section{static 宣告的意義}

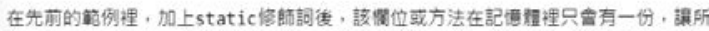

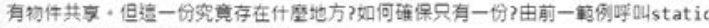

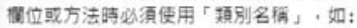

Circle1.PI

Circle1.areaformula(1) 
JAVA SE7/8 OCAJP. CHIO

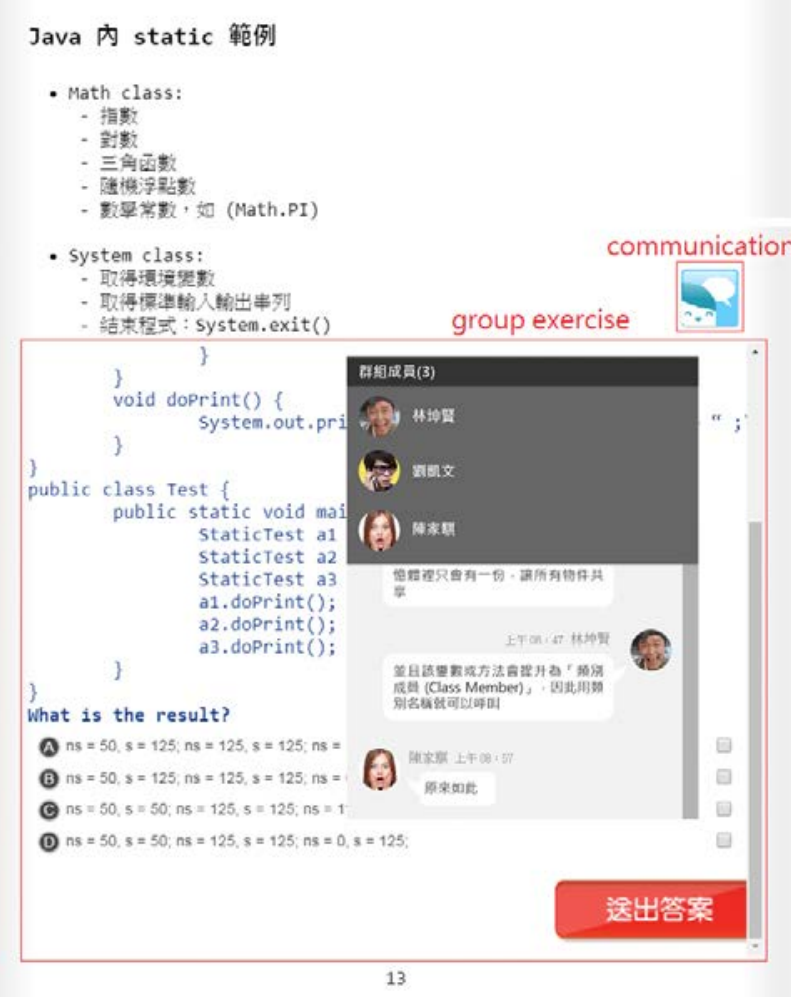

建立 Overloaded Method

\section{Method Signature}

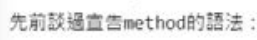

[modifiers] return_type method_identifier ( [arguments] ) $\{-\}$

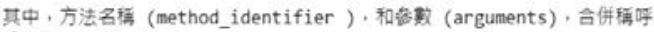

'Method Signature,

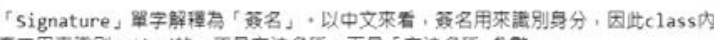

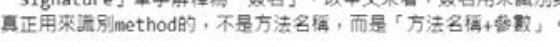

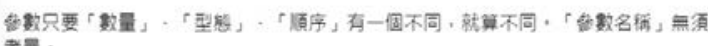

考電.

棵堂小秘挟

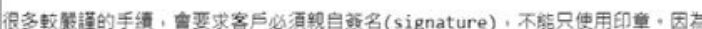

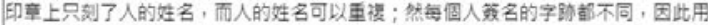

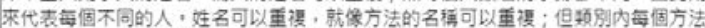

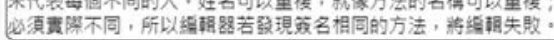

Figure 6. The eBook page 13-14 with embedded video and group exercise

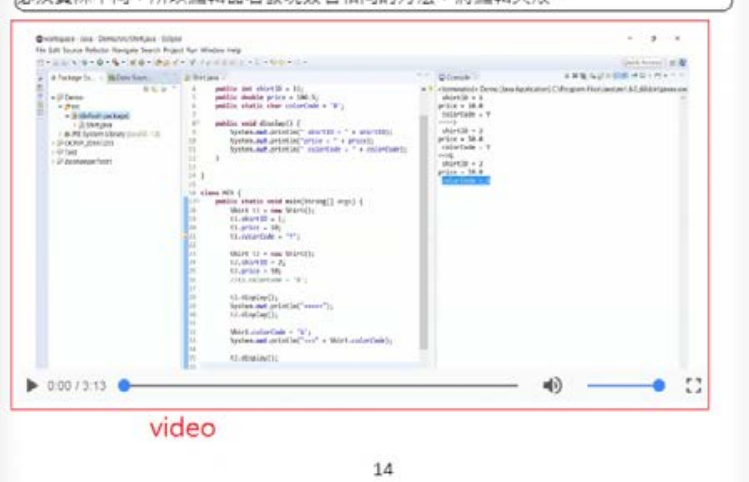

Figure 6. The eBook page 13-14 with embedded video and group exercise

\section{結果
$y=10$ \\ Shirt size = \\ Shirt size $=4$}

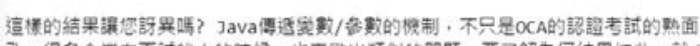

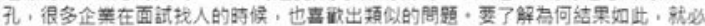

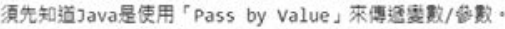

\section{Pass by Value}

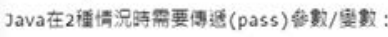

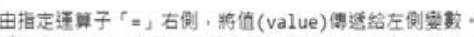

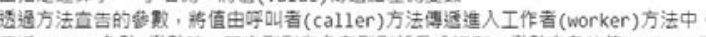

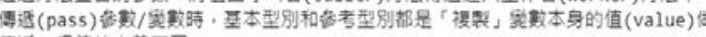

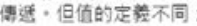

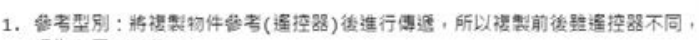
但揾问同一物件

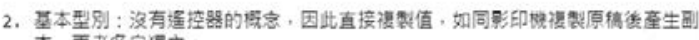
本、兩者各自盗立。

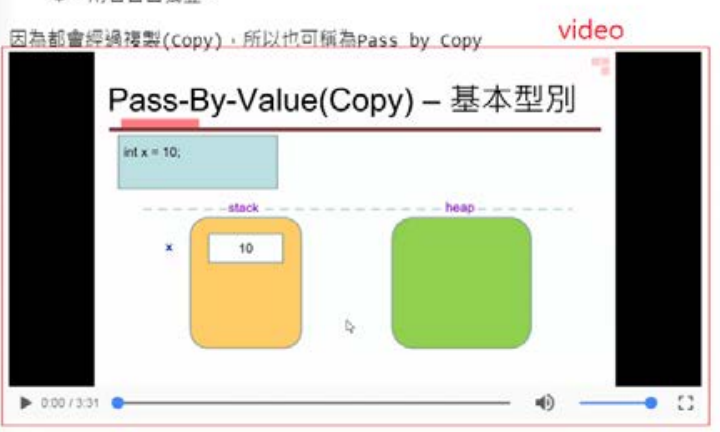

19
Pass-By-Value(Copy) - 本型別

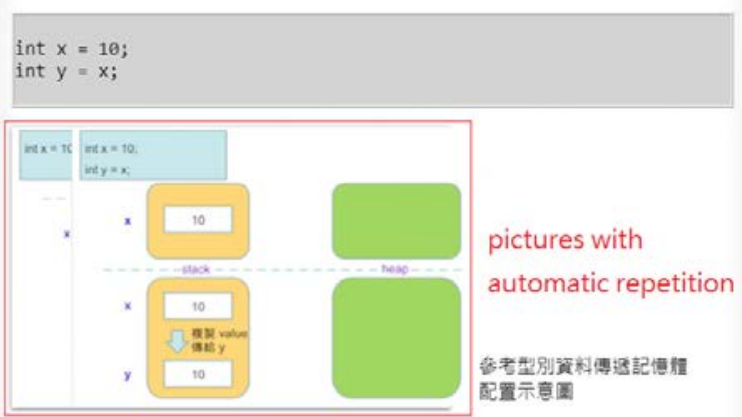

Shirt $x=$ new Shirt ()

shirt $y=x$;

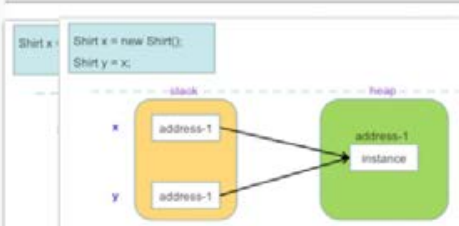

pictures with

automatic repetition

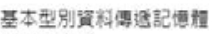
配置示要圆

Figure 7. The eBook page 19-20 with embedded video and automatic repetition 

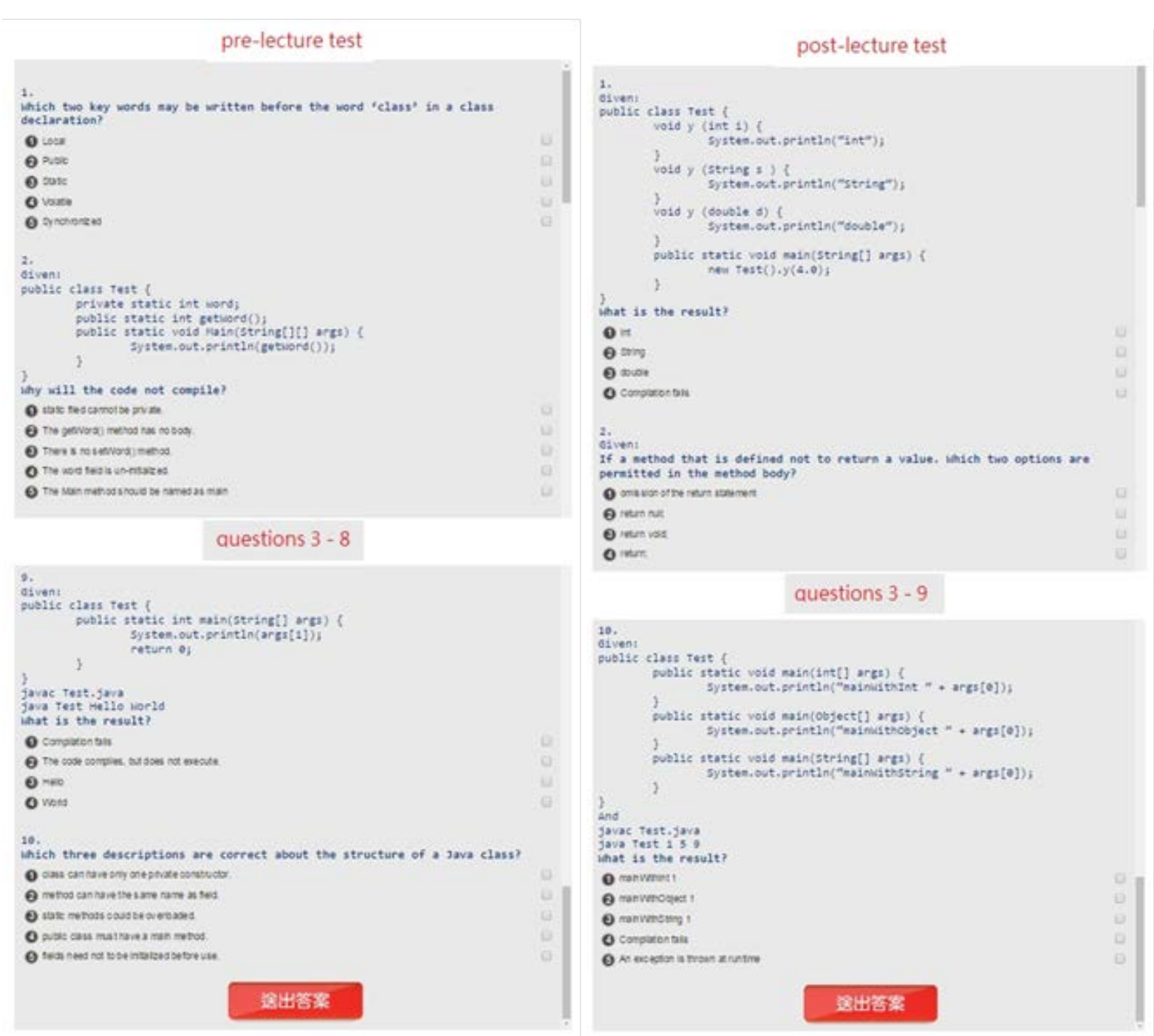

Figure 8. The pre-/post-lecture tests at the begin/end of the lesson

\section{The Course Instruction}

After designing the learning units and their respective learning activities and curricular contents for an 'ObjectOriented Concepts' course, this course was actually instructed then at the Spring semester in 2017 (according to the 5 th step of our approach) for freshman students at a Department of Information Management. 41 students enrolled in this course with all being the 18 - 19 ages, never learning object-oriented concepts, and also never experiencing the flip blended learning and eBooks. Further, 3 eBooks were created and used in the learning activities of each lesson unit - (1) a lecture-related eBook as shown in Figures 2 - 7 for the preview, lesson lecture, and exercises before and within the lesson, and (2) two assessment-related eBooks as shown in Figures $\mathbf{8}$ for the pre-/post-lecture test at the begin/end of the lesson. In particular, in addition to the teacher, a supportive teaching assistant is assigned in the lesson to provide students with such live helps as the manipulation of the eBooks (e.g., their embedded ePUB3 functions), the monitoring of the two pre-/post-lecture tests, and the advices of any exercises.

\section{The Course Assessment}

While the designed lessons are instructed with learning activities taken by enrolled students and curricular contents delivered via eBooks, respective outcome assessments are necessarily completed for verifying their effectiveness. In general, the outcome assessments of a lesson can be achieved by various ways such as exercises, assignments, or tests. 
Table 3. The 10 pre-lecture test questions about object methods and overloading

\begin{tabular}{|c|c|c|c|c|}
\hline \multirow{2}{*}{$\frac{\# \text { of Students - } 41}{\text { No. }}$} & \multicolumn{2}{|c|}{ \# of Valid Test - 41} & \multirow{2}{*}{\multicolumn{2}{|c|}{$\begin{array}{c}\text { Date }-04 / 14 / 2017 \\
\text { ratio of correctness }\end{array}$}} \\
\hline & \# of correctness & \# of error & & \\
\hline method declaration & & & Average & 0.81 \\
\hline 1 & 40 & 1 & 0.98 & \\
\hline 2 & 34 & 7 & 0.83 & \\
\hline 8 & 26 & 15 & 0.63 & \\
\hline 10 & 32 & 9 & 0.78 & \\
\hline method overloading & & & average & 0.90 \\
\hline 3 & 36 & 5 & 0.88 & \\
\hline 4 & 34 & 7 & 0.83 & \\
\hline 5 & 40 & 1 & 0.98 & \\
\hline method parameter passing & & & average & 0.81 \\
\hline 6 & 38 & 3 & 0.93 & \\
\hline 7 & 34 & 7 & 0.83 & \\
\hline 9 & 28 & 13 & 0.68 & \\
\hline
\end{tabular}

Table 4. The 10 post-lecture test questions about object methods and overloading

\begin{tabular}{ccccc}
\hline $\begin{array}{c}\text { \# of Students - 41 } \\
\text { No. }\end{array}$ & \# of correctness & \# of error & \multicolumn{2}{c}{ ratio of correctness } \\
\hline method declaration & & & average & 0.95 \\
\hline 2 & 37 & 3 & 0.93 & \\
\hline 3 & 38 & 2 & 0.95 & \\
\hline 5 & 38 & 2 & 0.95 & 0.97 \\
\hline 9 & 39 & 1 & 0.98 & \\
\hline method overloading & & & average & \\
\hline 1 & 39 & 1 & 0.98 & 0.95 \\
\hline 4 & 39 & 1 & 0.95 & \\
\hline 8 & 38 & 2 & average \\
\hline method parameter passing & & & 0.93 & \\
\hline 6 & 37 & 3 & 0.95 & \\
\hline 7 & 38 & 2 & 0.98 \\
\hline
\end{tabular}

For illustration, the 'Method \& Overloading' lesson completes its assessments by two tests: a pre-lecture test (for verifying the effectiveness of the preview before the lesson), and a post-lecture test (for verifying the learning effectiveness of the lecture and exercises in the lesson).

1. The pre-lecture test - as shown in Figure 8, the pre-lecture test consists of 10 multi-choice questions within three subjects - 'method declaration', 'method overloading', and 'method parameter passing' for verifying the preview effectiveness about students' comprehension on the concepts, overloads, and calls of object methods. As can be seen from Table 3, all ratios of correctness are above 0.8 and hence indicate that students have a good learning about object methods through the preview via ePUB3 functions. However, compared to the 'method overloading', the 'method declaration' and 'method parameter passing' have lower average ratios of correctness such that their learning may need to be improved in the lesson lecture via the supplemental instructions from the teacher.

2. The post-lecture test - as shown in Figure 8, the post-lecture test has also 10 multi-choice questions about the concepts, overloads, and calls of object methods (note that they are specifically designed within the same subjects and similar difficulties as those of the pre-lecture test for effecting the evaluation about the learning effectiveness of the lesson lecture). As can be seen from Table 4, all ratios of correctness are above 0.9 and hence indicate that students have an effective learning about object methods through the flip blended learning model via ePUB3 functions. In particular, compared to the pre-lecture test, the learning effectiveness about the 'method declaration' and 'method parameter passing' are improved significantly (via the supplemental instructions from the teacher) with their average ratio increased from 0.81 up to 0.95 , although that of the 'method overloading' is also improved from 0.90 up to 0.97 .

\section{THE VALIDITY OF THE APPROACH}

After the designed lessons have been instructed and respective assessments for verifying their effectiveness have also been completed, a follow-up analysis can then be taken (according to the 6th step of our approach) for 
Table 5. The questionnaire about the 'Method \& Overloading' lesson

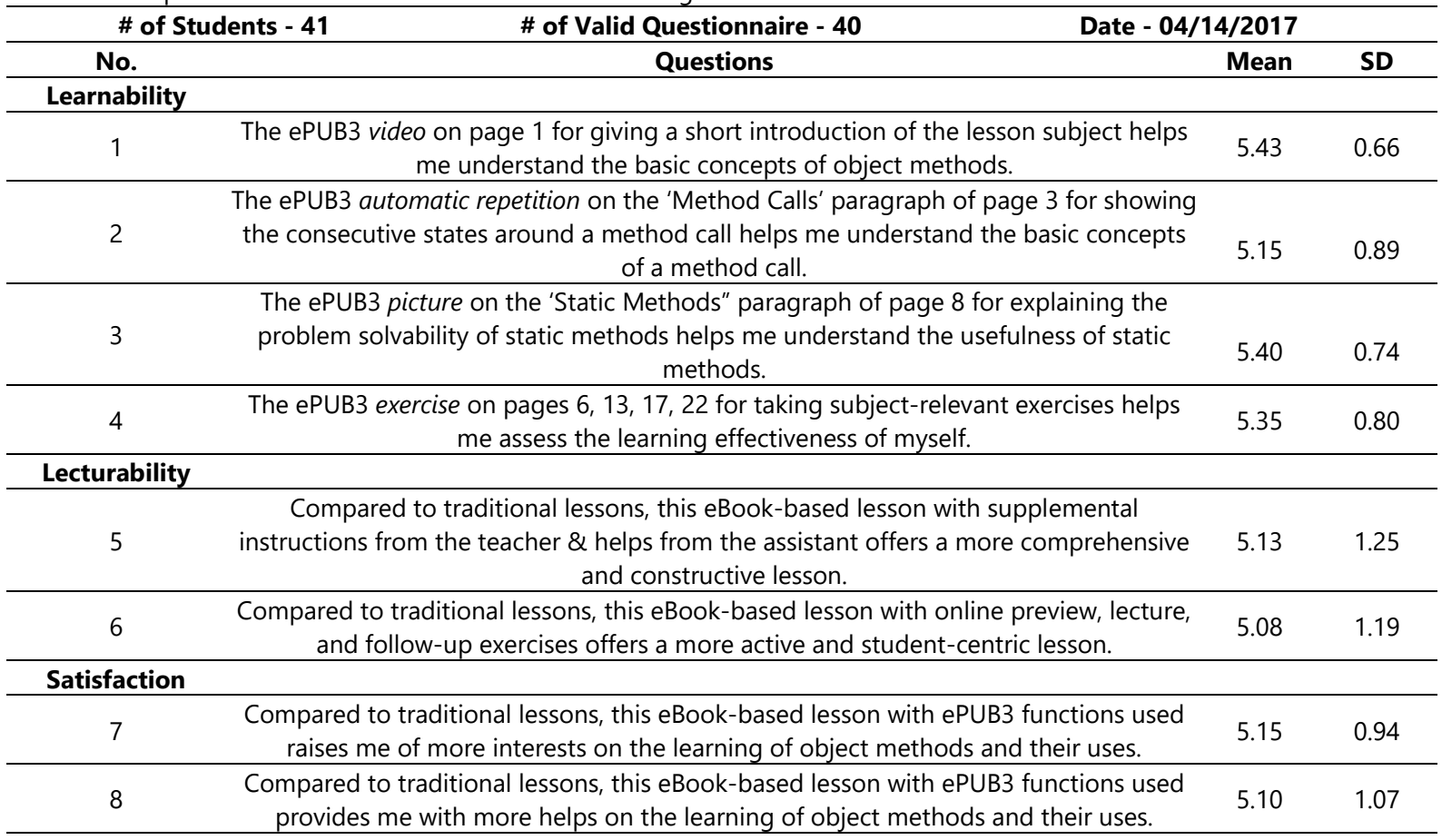

verifying the validity of using the ePUB3 eBook-based flip blended learning model in the actual instruction. In general, such a validity analysis for the instruction of a lesson can be achieved by two ways: (1) online questionnaires and in-person interviews with students for validating how these students think about the instruction (note that a questionnaire eBook is needed for delivering the desired questionnaires); and (2) exploring how these students participate in the instruction for validating the effects of their joining the ePUB3 eBook-based flip blended learning model.

For illustration, the validity analysis for the instruction of the 'Method \& Overloading' lesson is completed by the above two ways as described below.

1. The online questionnaire - as shown in Table 5, the questionnaire is completed by a questionnaire eBook that delivers 8 questions within three categories - 'Learnability' (of using ePUB3 eBooks), 'Lecturability' (of using the eBook-based flip blended model), and 'Satisfaction' (about using the eBook-based flip blended model) where a seven-point Likert scale, with $0=$ strongly disagree and $6=$ strongly agree, is used. As can also be seen from Table 5, all scores are above 5.0 and hence indicate that students have favourable attitudes towards enhancing their knowledge about object methods and their uses through the flip blended learning model via ePUB3 functions. In addition, students also advocate using ePUB3 eBooks in their learning, compared to the traditional textbooks, for raising them of more interests as well as providing them with more helps on the learning of object methods and their uses. Here a minor caveat can be noted that the mean value (and standard deviation) of question number 2 is lower (and also higher) than others because some students respond that the consecutive showing of pictures around a method call from the ePUB3 automatic repetition does not allow them to show backwards of these pictures while they try to go for viewing the pictures at their own order.

2. The in-person interview - as shown in Table 6, the interview is completed by asking 10 randomly selected (out of 41 enrolled) students for their opinions about using ePUB3 eBooks and the eBook-based flip blended model in their learning. As in the questionnaire, 8 questions are designed within the same three categories - 'Learnability', 'Lecturability', and 'Satisfaction'. Unsurprisingly, the interview results also show students' favourable attitudes towards using ePUB3 eBooks and the eBook-based flip blended model. They consider eBooks more interesting than traditional textbooks and hence can enhance better their learning effects. Further, they also advocate using the eBook-based flip blended model for its providing them with an effective learning under more helps from the eBooks and teacher/assistant. The following are some summaries of students' positive responses about the three categories of questions: 
Table 6. The interview about the 'Method \& Overloading' lesson

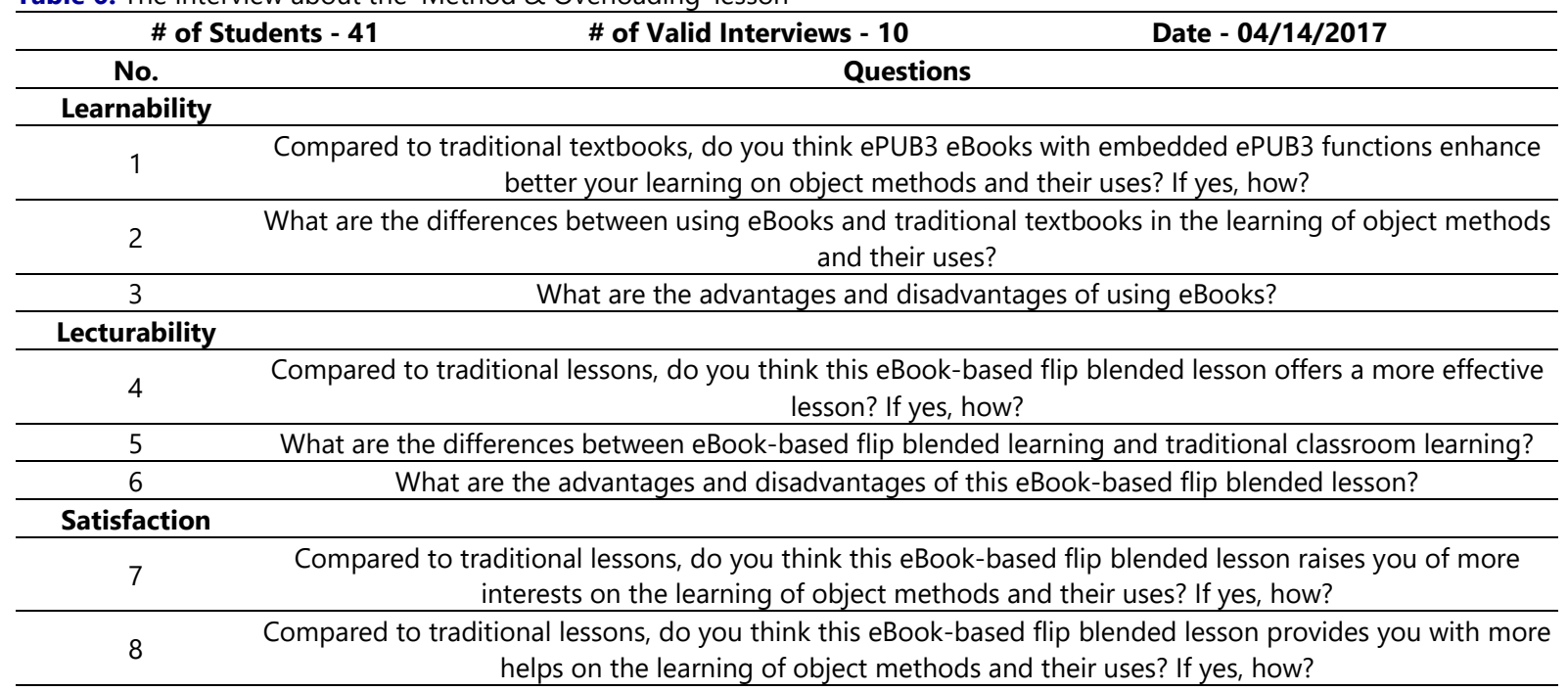

Learnability

(1) The eBook helps me understand better the class contents since it has many fantastic ways to deliver these contents.

(2) The eBook is more effective for me to learn; especially its embedded videos are much useful for me because I can watch them again and again until I can understand.

(3) The eBook is more convenient for me to learn because it makes me flexible to learn on my own pace.

Lecturability

(1) I like the preview because it allows me to get prepared before the class and then have time to think about what are lectured or discussed in the class.

(2) This is a new kind of learning. I need to read the class contents before the class and then get lectures and discussions in the class. This makes me understand better the class contents.

(3) I feel this way of learning is easier to comprehend the class contents; especially the supplemental lecture from the teacher is much useful for me to learn because I can get clarifications about what I could not understand in the preview.

Satisfaction

(1) The flip blended model can motivate me to learn more because I can actively involve in the learning.

(2) I like the flip blended model because I can learn on my own pace.

(3) I prefer the flip blended model because I can get more feedbacks or helps from the supplemental lecture and discussions in the class.

However, some negative responses from students can still be found as follows.

Learnability

(1) I still prefer to use the traditional textbook before I can get used to the eBook.

Lecturability

(1) The preview is very troublesome for me because I did always forget it during the 3 days for previewing. I think the teacher needs to force me to do it, otherwise I will always forget it.

Here from the above negative comments, we may conclude that some students may have old habits that hinder their using eBooks or joining the flip blended learning model. For this, some possible ways for encouraging or forcing them to use eBooks or join the flip blended learning model may need to be imposed in our approach.

3. Exploring how students' participate in the instruction - as shown in Table 7, this is illustratively completed by tracking their actions in the learning activities (e.g., acting on exercises and communications for taking the group exercise) and also their accesses on the deliveries of specific parts of curricular contents (e.g., reading textual pages or watching embedded videos). For this, students' actions/accesses on the Lecture eBook are tracked by such determinants as time points and number of times. Further, for judging the activeness of their actions/accesses, respective thresholds are set up for those determinants applicable to these 
Table 7. Students' in-lesson actions/accesses on the Lecture eBook

\begin{tabular}{|c|c|c|c|c|c|}
\hline \multirow{3}{*}{$\begin{array}{c}\text { Lesson Name } \\
\text { eBook } \\
\text { page }\end{array}$} & \multicolumn{5}{|c|}{ Method \& Overloading } \\
\hline & \multicolumn{5}{|c|}{ Lecture ePUB3 eBook } \\
\hline & page accesses & video accesses & repetition accesses & exercise actions & communication actions \\
\hline $1-2$ & $\mathrm{~T}: 88 \%(75 \%)$ & $\mathrm{N}: 90 \%(60 \%)$ & & & \\
\hline $3-4$ & $\mathrm{~T}: 90 \%(75 \%)$ & & $\mathrm{N}: 86 \%(60 \%)$ & & \\
\hline $5-6$ & T: $92 \%(75 \%)$ & & & $\mathrm{N}: 75 \%(60 \%)$ & \\
\hline $7-8$ & T: $92 \%(75 \%)$ & $\mathrm{N}: 84 \%(60 \%)$ & & & \\
\hline $13-14$ & T: $94 \%$ (75\%) & $\mathrm{N}: 72 \%(60 \%)$ & & $\mathrm{N}: 76 \%(60 \%)$ & $\mathrm{N}: 70 \%(60 \%)$ \\
\hline $19-20$ & T: $89 \%(75 \%)$ & $\mathrm{N}: 54 \%(60 \%)$ & $\mathrm{N}: 84 \%(60 \%)$ & & \\
\hline
\end{tabular}

note: $\mathrm{x} \%(\mathrm{y} \%)$ denotes the ratio of all students' actions/accesses reaching $\mathrm{x} \%$ with respect to the $\mathrm{y} \%$ threshold

actions/accesses. As shown in Table 7, students' in-lesson actions/ accesses are tracked by two determinants: $\mathrm{T}$ denotes the desired time point and $\mathrm{N}$ means the desired number of times. For instances, the activeness of accessing a specific part of the Lecture eBook (e.g., reading a pair of two consecutive pages or watching an embedded video) in the lesson can be determined by judging the ratio of all students' accesses on this part if it reaches the required thresholds of their determinants. Therefore, reading the pair of textual pages 1-2 is said active if the ratio of all students' reading these two pages in the lesson ( $\mathrm{T}$ - reading in the lesson) is higher than $75 \%$. In addition, watching an embedded video on pages 1-2 is said active if the ratio of all students' watching the video at least once ( $\mathrm{N}$ - watching at least once) is higher than $60 \%$. As results in Table 7, all in-lesson readings of textual pages are active in that they reach the threshold of $75 \%$ (i.e., all are $88 \%-94 \%)$. Further, watching an embedded video on pages $19-20$ is inactive due to its ratio $54 \%$ lower than the required $60 \%$ threshold. However, it is observed that watching the embedded videos on pages 12/7-8/13-14 are all active due to their ratios $90 \% / 84 \% / 72 \%$ higher than the $60 \%$ threshold.

In summary, with the above tracked students' in-lesson actions/accesses in Table 7, we may conclude that the actual instruction is valid for students to learn by their active actions in the group exercise and also their active accesses on all curricular contents (except for watching the video on pages 19-20) under our ePUB3 eBook-based flip blended learning model. As stated earlier, this also implies that some possible ways for encouraging or forcing students to watch the video on pages 19-20 may need to be imposed for improving the ratio of watching this video in later actual instructions.

\section{CONCLUSIONS}

In this paper, we presented a flip blended learning approach for designing, lecturing, and assessing academic courses with eBook-based ePUB3 functions used in learning activities for delivering desired curricular contents. In general, as a pilot discussion about using ePUB3 functions in learning activities, the approach is based on the blended course design issues in (McGee and Reis, 2012) as well as on the well-known ASSURE approach in (Smaldino, et al., 2012) with the following extensive considerations: (1) identifying the learning units of the course and the learning activities under the flip blended learning model for each lesson of a unit; (2) designing the lesson contents in respective eBooks to be delivered under these learning activities; (3) specifying the suitable ePUB3 functions embedded in such eBooks for supporting the actions of these learning activities and the deliveries of designed lesson contents; and (4) employing an analysis about the effects of using the extensive ePUB3 eBook-based flip blended learning model for justifying its validity. For implementation, the approach was applied for designing and instructing an 'Object-Oriented Concepts' course for freshman students at a Department of Information Management.

As a well-recognized paradigm, blended learning is widely accepted and adopted for its providing more supports on achieving learning objectives. For examples, it allows students to take the learning activities with both of online media and traditional learning platforms; students can therefore access more convenient environments for their autonomous learning and also if necessary more helps from the teacher. Since the course design developed by our approach addresses on the use of ePUB3 functions under the flip execution model of blended learning, its taking advantage of the multimedia and interactive features from the newly introduced ePUB3 techniques (ePUB3 Overview, 2011) can enhance the flip model with more flexible and attractive environments.

In our future work, we will continue to explore the application of our approach on the ePUB3 eBook-based course design for other academic tracks such as business, languages, arts, and general education. Further, in addition to the flip model used herein, its employing other execution models of blended learning will also be discussed. As presented in Section II, there are many other execution models on blended learning such as face-toface driver, rotation, online lab, flex, and online driver models. The usefulness and effectiveness of using these models in ePUB3 eBook-based courses will be respectively discussed. 


\section{REFERENCES}

@DreamBox_Learn, (2013). Six Models of Blended Learning. Retrieved from http://www.dreambox.com/blog/6models-blended-learning

Ally, M., Anderson, T., \& Elloumi, F. (2004). Foundations of Educational Theory for Online Learning. Theory and Practice of Online learning. Canada: AU Press, Athabasca Univ.

Alonso, F., Lopez, G., \& Manrique, D. (2005). Instructional Model for e-Learning with a Blended Learning Process Approach. British Journal of Educational Technology, 36(2), 217-235.

Banditvilai, C. (2016). Enhancing Students' Language Skills through Blended Learning. The Electronic Journal of eLearning, 14(3), 220-229.

Bermejo, B. (2005). Cooperative Electronic Learning in Virtual Laboratories through Forums, IEEE Transactions on Education, 48(1), 140-149.

Bersin, J. (2004). The Blended Learning Handbook. New York: Wiley.

Binas, M., Štancel, P., Novák, M., \& Michalko, M. (2012). Interactive eBook as a Supporting Tool for Education Process, Proc. of 10th IEEE International Conference on Emerging eLearning Technologies and Applications, Slovakia, 39-44.

Blank, G., Roy, S., Sahasrabudhe, S., Pottenger, W. M., \& Kessler, G. D. (2003). Adapting Multimedia for Diverse Student Learning Styles. Journal of Computing in Small Colleges, 18(3), 45-58.

Bonk, C., \& Graham, C. (2005). Handbook of Blended Learning: Global Perspectives, Local Designs. San Fransisco: Pfeiffer Publishing.

Bonk, C., \& Graham, C. (2006). The Handbook of Blended Learning. New York: Wiley.

Bressler, D., \& Bodzin, A. (2013). A Mixed Methods Assessment of Students' Flow Experiences during a Mobile Augmented Reality Science Game, Journal of Computer Assisted Learning, 29(6), 505-517.

Caeiro-Rodríguez, M., Perez-Rodriguez, P., Garcia-Alonso, J., \& Nistal, M. L. (2013). AREA: A Social Curation Platform for Open Educational Resources and Lesson Plans. Proc. of 2013 IEEE Conference on Frontiers in Education.

Cao, X., Zhao, P., \& Wang, X. (2009). Study on Design and Development of e-Learning System based on Learning Flow. Proc. of WRI World Congress on Software Engineering, 1, 367 - 371.

Chen, C., Huang, C., \& Chou, Y. (2017). Integrating Augmented Reality into Blended Learning for Elementary Science Course. Proc. of 5 th International Conference on Information and Education Technology.

Chen, C., Lee, I., \& Lin, L. (2015). Augmented Reality-based Self-Facial Modeling to Promote the Emotional Expression and Social Skills of Adolescents with Autism Spectrum Disorders. Research in Developmental Disabilities, 36, 396-403.

Chen, H., \& Chen, N. (2014). Design and Evaluation of a Flipped Course Adopting the Holistic Flipped Classroom Approach. Proc. of IEEE 14th International Conference on Advanced Learning Technologies, 627-631.

Clark, R., \& Mayer, R. (2011). E-Learning and the Science of Instruction: Proven Guidelines for Consumers and Designers of Multimedia Learning. New Jersey: John Wiley \& Sons.

Denner, J., Werner, L., \& Ortiz, E. (2012). Computer Games Created by Middle School Girls: Can They Be Used to Measure Understanding of Computer Science Concepts? Computers E Education, 58(1), 240-249.

Eke, K., \& Bell, M. (2010). Blended Course Design Made Easy: 3 Simple Steps. Proc. of 16th Annual Sloan Consortium International Conference on Online Learning.

ePUB3 Overview. (2011). Retrieved from http://www.idpf.org/epub/30/spec/

Gao, Z., \& Liu, H. (2010). Effective English Teaching and Learning via Web-based Electronic English Lesson Plan Design. Proc. of Second International Workshop on Education Technology and Computer Science, 358-361.

Hoic-Bozic, N. (2009). A Blended Learning Approach to Course Design and Implementation, IEEE Transactions on Education, 52(1), 19-30.

Hoyos-Rivera, G., Gomes, R. L., Willrich, R., \& Courtiat, J. P. (2006). CoLab: A New Paradigm and Tool for Collaboratively Browsing the Web. IEEE Transactions on Systems, Man, and Cybernetics - Part A: Systems and Humans, 36(6), 1074 - 1085.

Hybrid Course Development. (2017). Texas State University (TSU). Retrieved from http://www.its.txstate. edu/departments/instructional_design/hybrid-course-development.html

ISO/IEC JTC1 SC34. (2014). International Standardization Subcommittee for Document Description and Processing Languages. Retrieved from http://www.jtc1sc34.org/ 
ISO/IEC TS 30135. (2014). ePUB3 Overview. Retrieved from https://www.iso.org/standard/53255.html

Johnson, S. D., \& Aragon, S. R. (2002). An Instructional Strategy Framework for Online Learning Environments. Proc. of the Academy for Human Resource Development. Academy for Human Resource Development, 10221029.

Kharbach, M. (2014). The Four Important Models of Blended Learning Teachers Should Know About. Retrieved from http://www.educatorstechnology.com/2014/04/the-four-important-models-of -blended.html

Lee, I., Chen, C., \& Chang, K. (2016). Augmented Reality Technology Combined with Three-Dimensional Holography to Train The Mental Rotation Ability of Older Adults. Computers in Human Behavior, 65, 488500.

Li, Y., \& Liu, Y. (2010). Building an Online Course Based on Semantic Wiki for Hybrid Learning. Proc. of 3rd International Conference on Hybrid Learning, 217-228.

Lin, L. C., Tsai, T. P., Lin, J, \& Li., J. (2017). Some Useful ePUB3-based Contents Delivery Functions. Proc. of 5th International Conference on Information and Education Technology, 49-52.

Mao, C., Sun, C., \& Chen, C. (2017). Evaluate Learner's Acceptance of Augmented Reality Based Military Decision Making Process Training System, Proc. of 5th International Conference on Information and Education Technology.

Marinković, R., \& Tomaš, S. (2011). Formation of teaching content in E-learning, Proc. of 34th International Convention, MIPRO 2011, 1195 - 1200.

Martens, R., Gulikers, J., \& Bastiaens, T. (2004). The Impact of Intrinsic Motivation on e-Learning in Authentic Computer Tasks. Journal of Computer Assisted Learning, 20(5), 368-376.

McGee, P., \& Reis, A. (2012). Blended Course Design: A Synthesis of Best Practices, Journal of Asynchronous Learning Networks, 16(4), 7-22.

Mishra, S. (2002). A Design Framework for Online Learning Environments. British Journal of Educational Technology, 33(4), 493-496.

Morphew, V. (2000). Web-based Learning and Instruction: A Constructivist Approach, Distance Learning Technologies: Issues, Trends, and Opportunities, Idea Group, 1-15.

Online and Hybrid Course Development Guidelines. (2011). Cedar Crest College (CCU). Retrieved from http://www.cedarcrest.edu/ca/pdf/Online_and_Hybrid_Course_Development_Guidelines_2-10-11.pdf

Ortony, A., Collins, A. M., \& Clore, G. L. (1990). The Cognitive Structure of Emotions. Cambridge: Cambridge University Press, 59.

Poirier, S. (2010). A Hybrid Course Design: The Best of Both Educational Worlds, Techniques (ACTE), 85(6), $28-31$.

Ram, M., \& Sinha, A. (2017). An Implementation Framework for Flipped Classrooms in Higher Education, Proc. of the Special Collection on eGovernment Innovations in India (ICEGOV '17), 18-26.

Readium reader for ePUB3, (2017). Retrieved from http://readium.org/

Romero, L., Gutiérrez, M., \& Caliusco, L. (2014). Towards Semantically Enriched E-learning Assessment: Ontologybased Description of Learning Objects. Proc. of 14th IEEE International Conference on Advanced Learning Technologies, $336-338$.

Romero-Hall, E., Watson, G. S., Adcock, A., Bliss, J., \& Tufts, K. A. (2016). Simulated Environments with Animated Agents: Effects on Visual Attention, Emotion, Performance, and Perception. Journal of Computer Assisted Learning, 32(4), 360-273.

Rossett, A., Douglis, F., \& Frazee, R. (2003). Strategies for Building Blended Learning. ASTD. Retrieved from https://www. researchgate.net/publication/228550 955_Strategies_for_Building_Blended_Learning

Russell, J., Lowther, D., L., \& Smaldino, S., (2012). Instructional Technology and Media for Learning. New Jersey: Prentice Hall.

SCORM 2004, 4th Edition. (2015). Retrieved from https://www.adlnet.gov/adl-research/scorm/scorm-200 4-4thedition/

SCORM. (2015). Retrieved from https:/ /www.adlnet.gov/adl-research/scorm/

Stash, N., Cristea, A., \& De Bra, P. (2004). Authoring of Learning Styles in Adaptive Hypermedia: Problems and Solutions. Proc. of 13th International World Wide Web Conference, 114-123.

Stone, D., \& Zheng, G. (2014). Learning Management Systems in a Changing Environment, Handbook of Research on Education \& Technology in a Changing Society, chapter 56, IGI Global.

Thorne, K. (2003). Blended Learning. London: Kogan Page.

Vossen, G., \& Hagemann, S. (2010). Unleashing Web 2.0. the Netherlands: Elsevier. 
Ward, K., \& Draude, B. (2009). Instructional Design for Hybrid Courses: Deliberate Design for the Best of Both Worlds. Proc. of 14th Annual Instructional Technology Conference.

Wen, A., Zaid, N., \& Harun, J. (2016). Enhancing Students' ICT Problem Solving Skills using Flipped Classroom Model. Proc. of 2016 IEEE 8th International Conference on Engineering Education, 187-192.

Wikipedia. (2017). Comparison of eBook Formats. Retrieved from https://en.wikipedia.org/wiki/Comparis on_of_eBook_formats

Zhang, H., Meng, L., Han, X., Yuan, L., \& Wang, J. (2016). Exploration and Practice of Blended Learning in HVAC Course Based on Flipped Classroom. Proc. of 2016 International Symposium on Educational Technology, 84-88.

\section{http://www.ejmste.com}

